\title{
Produtividade de milho, espaçamento e modalidade de consorciação com Brachiaria brizantha em sistema plantio direto
}

\author{
Emerson Borghi( ${ }^{(1)}$ e Carlos Alexandre Costa Crusciol(1)
}

\author{
(1)Universidade Estadual Paulista, Fac. de Ciências Agronômicas, Campus de Botucatu, Caixa Postal 237, CEP 18603-970 Botucatu, SP. \\ E-mail: borghi@fca.unesp.br, crusciol@fca.unesp.br
}

\begin{abstract}
Resumo - O objetivo deste trabalho foi avaliar a influência, sobre a produtividade de grãos, da modalidade de consorciação da Brachiaria brizantha cultivar Marandu com a cultura do milho, em dois espaçamentos de semeadura, em sistema plantio direto. O experimento foi instalado em campo, em 2002/2003 e 2003/2004, na Fazenda Experimental Lageado (Unesp), Botucatu, SP. O delineamento experimental foi o de blocos ao acaso, em esquema fatorial simples $2 \times 4$, com quatro repetições. Os tratamentos foram dois espaçamentos entre linhas de milho (0,45 e 0,90 m) e quatro modalidades de cultivo: milho solteiro; milho com braquiária na linha de semeadura; milho com braquiária na entrelinha; e milho com braquiária simultaneamente na linha e na entrelinha. A modalidade de consórcio e o espaçamento utilizado não comprometem a absorção de nitrogênio, nem pelo milho nem pela forrageira. A produtividade de grãos de milho, no espaçamento de $0,45 \mathrm{~m}$, é menor com o consórcio da braquiária na linha e entrelinha simultaneamente. Conforme o ano agrícola, a produtividade de grãos é maior no espaçamento reduzido, quando consorciado com braquiária, independentemente da modalidade.
\end{abstract}

Termos para indexação: Zea mays, sistema de cultivo, integração lavoura-pecuária, consórcio.

\section{Corn yield, spacing and intercropping modalities with Brachiaria brizantha in no-tillage system}

\begin{abstract}
The objective of this research was to evaluate the effects on corn yield of different modes of corn intercropping with Brachiaria brizantha cv. Marandu. The experiment was carried out in field conditions, in 2002/2003 and 2003/2004, at Fazenda Experimental Lageado (Unesp), in Botucatu, SP, Brazil. The experimental design was the randomized complete block, as a factorial $2 \times 4$, with four replications. The treatments were two row spacings of corn $(0.45$ and $0.90 \mathrm{~m})$ and four intercropping modalities: single corn; corn intercropped with $B$. brizantha in the row of sowing; corn intercropped with $B$. brizantha in space between two rows; and corn intercropped simultaneously with $B$. brizantha in the row and in the inter-row. The consortium modalities and the spacing used did not damage nitrogen absorption, neither for the corn nor the forage. Corn grains productivity in $0.45 \mathrm{~m}$ row spacing was lower with the row and inter-row Brachiaria consortium. Depending on agricultural year, grain yield is greater in the reduced row spacing, when intercropping with Brachiaria, independently of the modality.
\end{abstract}

Index terms: Zea mays, tillage systems, crop-livestock integration, consortium.

\section{Introdução}

No sistema de integração lavoura-pecuária, por meio da consorciação de duas gramíneas, a forrageira tem a função de fornecer alimento para a exploração pecuária, a partir do final do verão até início da primavera, e, posteriormente, de formação de palhada, para o cultivo da cultura produtora de grãos, em sistema plantio direto. Esse sistema pode vir a ser uma alternativa para o agricultor ou agropecuarista, visto que em muitas regiões do Brasil o cultivo de safrinha tem apresentado insucesso, face à baixa disponibilidade hídrica e irregularidade na precipitação pluvial no período outono/inverno (Zanine et al., 2006).

O consórcio de culturas produtoras de grãos e forrageiras tropicais é possível, graças ao diferencial de tempo e espaço, no acúmulo de biomassa entre as espécies (Kluthcouski \& Yokoyama, 2003). De acordo com Jakelaitis et al. (2004), a competição existente entre 
as espécies pode inviabilizar o cultivo consorciado. Porém, o conhecimento no comportamento das espécies, pela competição por fatores de produção, torna-se de grande importância para o êxito na formação da pastagem no período de outono-inverno, e para a produção satisfatória da cultura produtora de grãos.

Trabalhos com o cultivo consorciado de milho e Brachiaria brizantha demonstram a viabilidade deste sistema de produção. Cobucci et al. (2001) relatam que a presença da forrageira não afetou a produtividade de grãos de milho. Porém, em alguns casos, houve necessidade da aplicação de nicossulfuron, em subdoses, para reduzir o crescimento da forrageira e garantir pleno desenvolvimento do milho. No caso do cultivo consorciado, esta competitividade pode ser amenizada com adoção de práticas culturais, como o arranjo espacial de plantas (Oliveira et al., 1996), que retarda sobremaneira o acúmulo de biomassa por parte da forrageira, durante o período de competição interespecífica.

A redução do espaçamento de semeadura entre linhas propicia melhor distribuição espacial de plantas de milho (Sangoi et al., 2002) e melhor produção de forragem, aliada à maior cobertura do solo.

Além disso, a consorciação das forrageiras pode promover a supressão na emergência das plantas daninhas, em virtude da agressividade na formação dessas espécies forrageiras após a colheita da cultura produtora de grãos (Jakelaitis et al., 2004; Freitas et al., 2005).

Há trabalhos que evidenciam a vantagem do cultivo consorciado com as culturas da soja e do milho, em que foram utilizadas doses reduzidas de herbicidas aplicados no período de pós-emergência (Silva et al., 2004; Freitas et al., 2005; Jakelaitis et al., 2005; Silva \& Benez, 2005), porém, Kluthcouski et al. (2000) relataram que a deposição do fertilizante de semeadura, misturado com as sementes da espécie forrageira, em maiores profundidades, permite o atraso da emergência, de maneira a diminuir a competição com a cultura produtora de grãos.

Contudo, há carência, nesse sistema de produção agrícola, de informações quanto ao espaçamento mais adequado para a cultura do milho e quanto à modalidade mais adequada de consorciação com a forrageira.

Este trabalho teve por objetivo avaliar a influência da modalidade de consorciação da Brachiaria brizantha cultivar Marandu com a cultura do milho, em dois espaçamentos de semeadura, em sistema plantio direto.

\section{Material e Métodos}

O experimento foi realizado sob condições de sequeiro, nos anos agrícolas 2002/2003 e 2003/2004, na Fazenda Experimental Lageado da Faculdade de Ciências Agronômicas, Unesp, Campus de Botucatu, SP, a $22^{\circ} 51^{\prime} \mathrm{S}$ e $48^{\circ} 26^{\prime} \mathrm{W}$, e $740 \mathrm{~m}$ de altitude. O clima predominante na região é do tipo Cwa, segundo de Köppen, ou seja, tropical de altitude, com inverno seco e verão quente e chuvoso (Lombardi Neto \& Drugowich, 1994). O solo da área experimental é um Nitossolo Vermelho estruturado (Embrapa, 1999), manejado há seis anos em sistema plantio direto.

O delineamento experimental foi o de blocos ao acaso, em esquema fatorial simples $2 \times 4$, com quatro repetições. Os tratamentos constituíram-se da combinação de dois espaçamentos entre linhas de milho $(0,45$ e $0,90 \mathrm{~m})$ e quatro modalidades de cultivo: sistema MBL, cultivo do milho com braquiária na linha de semeadura; $\mathrm{MBE}$, cultivo do milho com braquiária na entrelinha; MBLE, cultivo do milho com braquiária simultaneamente na linha e na entrelinha; e MCS, cultivo do milho solteiro (testemunha).

Cada unidade experimental teve área total de $120 \mathrm{~m}^{2}$ (20 m de comprimento x $6 \mathrm{~m}$ de largura). O híbrido de milho utilizado foi o AG 9010, e a espécie forrageira foi a Brachiaria brizantha Stapf cv. Marandu. Antes da instalação do experimento, setembro de 2002, foram coletadas amostras de solo na camada de 0 a 0,20 m de profundidade, para a análise química de rotina, para fins de fertilidade, conforme Raij \& Quaggio (1983). Os resultados revelaram as seguintes características: $\mathrm{pH}\left(\mathrm{CaCl}_{2}\right) 4,8 ; 34 \mathrm{~g} \mathrm{~kg}^{-1}$ de MO; $30 \mathrm{mg} \mathrm{dm}^{-3} \mathrm{de} \mathrm{P}$ (resina); $1,5 \mathrm{mmol}_{\mathrm{c}} \mathrm{dm}^{-3}$ de $\mathrm{K} ; 39 \mathrm{mmol}_{\mathrm{c}} \mathrm{dm}^{-3} \mathrm{de} \mathrm{Ca}$; $14 \mathrm{mmol}_{\mathrm{c}} \mathrm{dm}^{-3} \mathrm{de} \mathrm{Mg} ; 47 \mathrm{mmol}_{\mathrm{c}} \mathrm{dm}^{-3} \mathrm{de} \mathrm{H}+\mathrm{Al}$, e $53 \%$ de V. De acordo com as recomendações de Raij et al. (1996), para a cultura do milho, realizou-se a calagem superficial, em 15/10/2002, sobre o resíduo vegetal remanescente na área, na dose de $2.500 \mathrm{~kg} \mathrm{ha}^{-1} \mathrm{de}$ calcário dolomítico (PRNT $=90 \%$ ), com o objetivo de elevar a saturação por bases a $70 \%$.

Em 11/12/2002, a cobertura vegetal da área (milheto) foi dessecada por meio da aplicação de glifosato (1.800 $\mathrm{g} \mathrm{ha}^{-1}$ do i.a.), com volume de calda de $250 \mathrm{~L} \mathrm{ha}^{-1}$. A semeadura da cultura do milho solteiro e em consórcio com braquiária foi realizada em 13/12/2002 e 13/12/2003, respectivamente, por meio de semeadora-adubadora para plantio direto, com cinco linhas espaçadas em $0,45 \mathrm{~m}$ e três linhas 
espaçadas em 0,90 m, para a obtenção de estande de 55.000 plantas ha-1, tendo-se adotado $5 \mathrm{~cm}$ de profundidade de deposição da semente de milho. A densidade de semeadura da braquiária foi de $10 \mathrm{~kg} \mathrm{ha}^{-1}$ $(\mathrm{VC}=34 \%)$, independentemente da forma de consorciação, e as sementes foram misturadas ao adubo e acondicionadas no compartimento de fertilizante da semeadora, distribuídas à profundidade de $8 \mathrm{~cm}$, localizada abaixo da semente de milho, conforme Kluthcouski et al. (2000).

No segundo ano (2003/2004), o experimento foi instalado na mesma área, ou seja, todos os tratamentos foram implantados no mesmo local do ano anterior. Assim, a cultura foi semeada sobre palhada de $8.979 \mathrm{~kg} \mathrm{ha}^{-1}$ de braquiária, na média das modalidades de consórcio, e $2.030 \mathrm{~kg} \mathrm{ha}^{-1}$ de vegetação espontânea, no tratamento de milho solteiro. A dessecação das parcelas com braquiária foi realizada por meio da aplicação do herbicida glifosato (1.800 $\mathrm{g} \mathrm{ha}^{-1}$ do i.a.), com volume de calda de $250 \mathrm{~L} \mathrm{ha}^{-1}$. Aos 20 dias após essa operação, constatou-se que não houve rebrota da braquiária.

A emergência do milho ocorreu em 19/12/2002 e $22 / 12 / 2003$, enquanto a braquiária teve sua emergência em 5/1/2003 e 28/12/2003. Essa diferença de tempo na emergência das espécies foi decorrente da maior profundidade de deposição da forrageira no solo.

No espaçamento de $0,90 \mathrm{~m}$, a semeadura de braquiária, na entrelinha e na linha mais entrelinha, foi realizada utilizando-se todos os carrinhos da semeadora a 0,45 m. Assim, alternadamente um carrinho distribuía somente milho e outro somente braquiária (MBE, cultivo do milho com braquiária na entrelinha) ou milho e braquiária e outro somente braquiária (MBLE, cultivo do milho com braquiária simultaneamente na linha e na entrelinha). Quanto ao espaçamento de $0,45 \mathrm{~m}$, a semeadura de braquiária na entrelinha e na linha mais entrelinha foi realizada com uso de todos os carrinhos da semeadora a $0,45 \mathrm{~m}$. No entanto, houve a necessidade de se passar a semeadora na entrelinha da primeira passada, para estabelecer o espaçamento de 0,225 m entre a linha de milho e a de braquiária para os tratamentos MBE e MBLE.

As adubações de semeadura nos dois anos agrícolas foram realizadas por área, assim, houve a necessidade de diferentes regulagens de distribuição de fertilizante, em razão dos tratamentos empregados. A adubação mineral de semeadura constou da aplicação de $20 \mathrm{~kg} \mathrm{ha}^{-1}$ de $\mathrm{N}, 70 \mathrm{~kg} \mathrm{ha}^{-1}$ de $\mathrm{P}_{2} \mathrm{O}_{5}$ e $40 \mathrm{~kg} \mathrm{ha}^{-1} \mathrm{de}_{2} \mathrm{O}$, correspondentes a $250 \mathrm{~kg} \mathrm{ha}^{-1} \mathrm{do}$ fertilizante formulado 8-28-16.
Logo após a emergência das plântulas no campo, foi efetuada a aplicação em área total do inseticida Spinosad, na dosagem de $20 \mathrm{~g} \mathrm{ha}^{-1}$ do i.a., para o controle da lagarta do cartucho (Spodoptera frugiperda) e, simultaneamente a esta operação, realizou-se o controle de plantas daninhas em pós-emergência, com adição, à calda, do herbicida Atrazina, na dosagem de $2 \mathrm{~L} \mathrm{ha}^{-1}$ do i.a. A aplicação dos produtos foi realizada por meio de pulverizador tratorizado de barras com $12 \mathrm{~m}$ de comprimento, tendo-se utilizado bicos leque espaçados em $0,50 \mathrm{~m}$ e pressão de $50 \mathrm{psi}$.

Quando a cultura do milho atingiu o estádio fenológico de cinco folhas desenvolvidas aos 25 dias após a emergência (DAE), procedeu-se à adubação de cobertura, com aplicação manual de $90 \mathrm{~kg} \mathrm{ha}^{-1}$ de $\mathrm{N}$, correspondentes a aproximadamente $450 \mathrm{~kg} \mathrm{ha}^{-1}$ do fertilizante sulfato de amônio (Raij et al., 1996), para produtividade de 6 a $8 \mathrm{t} \mathrm{ha}^{-1}$ de grãos e classe de resposta alta.

A amostragem para diagnose foliar do milho e de braquiária, para a determinação dos teores de $\mathrm{N}$ nas folhas das espécies, foi efetuada no momento em que mais de 50\% das plantas de milho encontravam-se pendoadas e com presença de estilo-estigmas. Para tanto, fez-se a coleta da folha oposta à espiga superior, conforme Malavolta et al. (1997), em dez plantas por unidade experimental. No caso da braquiária, coletouse a parte aérea das plantas, concomitantemente à amostragem do milho, para se determinar a produção de matéria seca em $2 \mathrm{~m}$, em duas linhas por unidade experimental.

Durante a condução do experimento, determinouse a precipitação pluvial e as temperaturas máxima e mínima. Nos anos de 2003 e 2004, as temperaturas máximas foram de 26,5 e $25^{\circ} \mathrm{C}$, mínima de 17 e $16^{\circ} \mathrm{C}$, e a precipitação pluvial anual de 1.455 e $1.330 \mathrm{~mm}$, respectivamente.

A colheita do milho em 2002/2003 foi realizada em 26/4/2003, 125 DAE do milho e 110 DAE da braquiária. Em 2003/2004, a colheita foi realizada aos 132 DAE do milho e 122 DAE da braquiária.

As variáveis avaliadas foram: estande final de plantas, índice de espigas, número de grãos por espiga, massa de 100 grãos e produtividade de grãos (13\% de umidade).

Os resultados obtidos foram submetidos à análise de variância, e as médias foram comparadas pelo teste DMS, a $5 \%$ de probabilidade. 


\section{Resultados e Discussão}

Na Tabela 1, estão contidos os resultados referentes aos teores de $\mathrm{N}$ nas folhas de milho e de braquiária, bem como a produção de matéria seca da forrageira. Verifica-se que no ano agrícola 2003/2004 houve efeito da interação dos fatores. No desdobramento da interação modalidades de cultivo dentro de espaçamentos, os cultivos consorciados promoveram aumentos nos teores de $\mathrm{N}$ em ambos os espaçamentos, quando comparados ao sistema de cultivo do milho solteiro (Tabela 2). Quanto ao desdobramento espaçamentos entre linhas dentro de modalidades de consorciação, verifica-se que no consórcio MBL o teor de $\mathrm{N}$ para o milho foi superior no espaçamento de $0,45 \mathrm{~m}$, tendo ocorrido o inverso para a modalidade MBLE, o que pode estar relacionado à maior produtividade de matéria seca da forrageira no período de outono-inverno, no ano anterior, nesses sistemas. Apesar desse efeito significativo, pelos valores descritos por Malavolta et al. (1997), os teores estão dentro do intervalo considerado adequado para a cultura do milho (Tabela 1).

Quanto aos teores de $\mathrm{N}$ na braquiária, os valores são maiores do que os considerados adequados para a forrageira (Raij et al., 1996). Tal fato não era esperado, em virtude da exigência de $\mathrm{N}$ pela cultura do milho, principalmente quando semeado sob palhada proveniente de gramíneas com alta relação $\mathrm{C} / \mathrm{N}$. Em virtude da consorciação entre o milho e a forrageira, era esperado que pudessem ocorrer diferenças expressivas entre as modalidades de cultivo, em virtude da grande exigência de $\mathrm{N}$ por ambas as espécies. Entretanto, ao realizar a adubação de cobertura (90 kg ha-1 de N), com o uso de sulfato de amônio $\left(\mathrm{NH}_{4} \mathrm{SO}_{4}\right)$ (Raij et al., 1996), para atingir alta produtividade de grãos, não houve limitação deste nutriente para as espécies.

Ao se compararem os resultados dos dois anos de cultivo, constata-se que os teores de $\mathrm{N}$, em ambas as espécies, apesar de estarem dentro da faixa considerada adequada, foram menores em todos os tratamentos, no segundo ano agrícola. Esse resultado, provavelmente, é decorrente do cultivo sucessivo de gramíneas, o que proporciona a imobilização do N.

As doses de $\mathrm{N}$ para suprir a demanda pelas culturas variam em função do ambiente de cultivo e do sistema de rotação, e são maiores quando a rotação é realizada somente com gramíneas. Por sua vez, o cultivo consorciado com gramíneas produtoras de grãos e plantas forrageiras, no sistema plantio direto, pode aumentar a quantidade de $\mathrm{N}$ necessária para o adequado crescimento da cultura principal, pois, além de ocorrer imobilização de $\mathrm{N}$ por microrganismos do solo, no processo de decomposição da cobertura morta, há maior demanda pelo nutriente, quando duas espécies são cultivadas simultaneamente no mesmo ambiente. Os valores encontrados permitem inferir que, em condições de cultivo consorciado, desde que bem realizado, a competição por nutrientes é pequena entre as

Tabela 1. Médias de teor de nitrogênio nas folhas de milho e de Brachiaria brizantha, por ocasião da inflorescência do milho, em cultivo consorciado em sistema plantio direto, e produção de matéria seca (MS) da B. brizantha, nos anos agrícolas de 2002/ 2003 e $2003 / 2004^{(1)}$.

\begin{tabular}{|c|c|c|c|c|c|c|}
\hline \multirow[t]{3}{*}{ Tratamento } & \multicolumn{4}{|c|}{ Teor de $\mathrm{N}$ foliar } & \multicolumn{2}{|c|}{ MS de $B$. brizantha } \\
\hline & \multicolumn{2}{|c|}{ Milho } & \multicolumn{2}{|c|}{ B. brizantha } & \multirow[t]{2}{*}{$2002 / 2003$} & \multirow[t]{2}{*}{$2003 / 2004$} \\
\hline & 2002/2003 & 2003/2004 & 2002/2003 & $2003 / 2004$ & & \\
\hline \multicolumn{7}{|c|}{ Espaçamentos (E) (m) } \\
\hline 0,90 & $37,3 \mathrm{a}$ & $31,9 \mathrm{a}$ & $27,4 \mathrm{a}$ & $23,4 a$ & $4.732 \mathrm{a}$ & $3.800 \mathrm{a}$ \\
\hline$\underline{0,45}$ & $40,1 \mathrm{a}$ & $32,3 \mathrm{a}$ & $27,1 \mathrm{a}$ & $21,8 \mathrm{a}$ & $2.740 \mathrm{~b}$ & $3.822 \mathrm{a}$ \\
\hline \multicolumn{7}{|c|}{ Modalidade de cultivo (MC) } \\
\hline $\mathrm{MCS}$ & $39,0 \mathrm{a}$ & $30,7 b$ & & & & \\
\hline MBL & $39,4 \mathrm{a}$ & $33,1 \mathrm{a}$ & $29,0 \mathrm{a}$ & $24,4 \mathrm{a}$ & $3.541 \mathrm{a}$ & $4.033 \mathrm{a}$ \\
\hline MBE & $38,6 a$ & $33,2 \mathrm{a}$ & $26,5 \mathrm{a}$ & $22,8 \mathrm{a}$ & $3.418 \mathrm{a}$ & $4.250 \mathrm{a}$ \\
\hline MBLE & $38,1 \mathrm{a}$ & $31,6 \mathrm{~b}$ & $26,4 \mathrm{a}$ & $21,9 \mathrm{a}$ & $3.709 \mathrm{a}$ & $4.650 \mathrm{a}$ \\
\hline \multicolumn{7}{|l|}{ DMS } \\
\hline $\mathrm{E}$ & 2,9 & 0,8 & 2,8 & 2,3 & 1.146 & 706 \\
\hline $\mathrm{MC}$ & 1,4 & 1,2 & 3,4 & 2,9 & 1.404 & 864 \\
\hline $\mathrm{CV}(\%)$ & 10,4 & 3,5 & 11,6 & 7,0 & 37,0 & 18,9 \\
\hline
\end{tabular}


espécies, independentemente da modalidade de consórcio empregado.

Com relação à produtividade de matéria seca de braquiária no momento do estádio de pendoamento do milho, constatou-se o efeito significativo apenas no primeiro ano agrícola, em que o espaçamento de $0,90 \mathrm{~m}$ proporcionou maior produção em relação a $0,45 \mathrm{~m}$ (Tabela 1).

Em relação ao estande final de plantas, verificou-se que somente no segundo ano agrícola (2003/2004) as modalidades de consorciação influenciaram essa variável, tendo ocorrido a interação entre os fatores (Tabela 3). No desdobramento da interação, verificou-se que a redução no espaçamento proporcionou maior estande final na modalidade de consorciação na entrelinha, porém, no consórcio do milho com a forrageira, na linha, o comportamento foi inverso (Tabela 4). O cultivo consorciado do milho com a braquiária na linha mais entrelinha proporcionou menor estande de plantas, nos dois espaçamentos,

Tabela 2. Desdobramento da interação de modalidades de cultivo $\mathrm{x}$ espaçamentos entre linhas referente ao teor foliar de nitrogênio do milho consorciado com Brachiaria brizantha, em sistema plantio direto, no ano agrícola 2003/ $2004^{(1)}$.

\begin{tabular}{ccccc}
\hline \multirow{2}{*}{$\begin{array}{c}\text { Espaçamento } \\
(\mathrm{m})\end{array}$} & \multicolumn{4}{c}{ Modalidades de cultivo } \\
\cline { 2 - 4 } & $\mathrm{MCS}$ & \multicolumn{4}{c}{ MBL } & MBE & MBLE \\
\hline & & Nitrogênio & $\left(\mathrm{g} \mathrm{kg}^{-1}\right)$ \\
0,90 & $30,7 \mathrm{aB}$ & $31,4 \mathrm{bAB}$ & $32,9 \mathrm{aA}$ & $32,7 \mathrm{aA}$ \\
0,45 & $30,7 \mathrm{aB}$ & $34,8 \mathrm{aA}$ & $33,5 \mathrm{aA}$ & $30,6 \mathrm{bB}$
\end{tabular}

(1)Médias seguidas por letras iguais, maiúsculas nas linhas e minúsculas nas colunas, não diferem entre si pelo teste DMS, a 5\% de probabilidade; MCS: milho solteiro; MBL: milho + B. brizantha na linha; MBE: milho + B. brizantha na entrelinha; MBLE: milho + B. brizantha na linha e entrelinha; DMS $=1,6 \mathrm{~g} \mathrm{~kg}^{-1}$. assim como o consorciado na linha no espaçamento de $0,45 \mathrm{~m}$, provavelmente, pela maior competição existente entre as espécies durante o desenvolvimento inicial do milho.

No primeiro ano agrícola, o índice de espigas não foi influenciado pelos fatores, entretanto, no segundo ano agrícola, essa variável foi influenciada pela interação entre os fatores (Tabela 3). No desdobramento da modalidade de cultivo dentro de espaçamento, constatou-se efeito apenas no espaçamento de $0,45 \mathrm{~m}$, em que as modalidades de consórcio, na entrelinha e na linha mais entrelinha, proporcionaram os menores valores de estande de plantas e diferiram do cultivo do milho solteiro (Tabela 4). Esse efeito pode estar relacionado à maior competição da forrageira com as plantas de milho pois, nessas duas modalidades, a forrageira se desenvolve na entrelinha e recebe menor competição do milho, principalmente quanto ao sombreamento na fase inicial de desenvolvimento. No desdobramento do espaçamento dentro de modalidades, para o índice de espigas, constatou-se efeito apenas no cultivo do milho solteiro, em que o espaçamento de $0,45 \mathrm{~m}$ proporcionou o maior valor. Esse resultado pode ser explicado pelo melhor arranjo espacial das plantas de milho, associado à menor competição por parte das plantas de braquiária.

A redução no espaçamento entre linhas e as modalidades de consorciação empregadas não provocou diferenças entre os valores de número de grãos por espiga, no primeiro ano de condução do experimento (Tabela 5). No ano agrícola 2003/2004, o número de grãos por espiga sofreu influência das modalidades de consorciação, em que o cultivo do milho com a

Tabela 3. Médias de estande final de plantas e de índice de espigas de milho consorciado com Brachiaria brizantha, em sistema plantio direto, nos anos agrícolas de 2002/2003 e 2003/2004(1).

\begin{tabular}{|c|c|c|c|c|}
\hline \multirow[t]{3}{*}{ Tratamento } & \multicolumn{2}{|c|}{ Estande final } & \multicolumn{2}{|c|}{ Índice de espigas } \\
\hline & $2002 / 2003$ & $2003 / 2004$ & $2002 / 2003$ & $2003 / 2004$ \\
\hline & \multicolumn{2}{|c|}{ 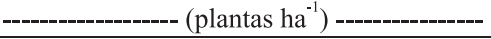 } & \multicolumn{2}{|c|}{------ (número de espigas por planta) ------ } \\
\hline \multicolumn{5}{|c|}{ Espaçamento (E) (m) } \\
\hline 0,45 & $51.180 \mathrm{a}$ & $55.147 \mathrm{a}$ & $0,956 \mathrm{a}$ & $0,987 \mathrm{a}$ \\
\hline \multicolumn{5}{|c|}{ Modalidade de cultivo (MC) } \\
\hline MCS & $46.271 \mathrm{a}$ & $57.891 \mathrm{a}$ & $0,975 \mathrm{a}$ & $1,008 \mathrm{a}$ \\
\hline MBL & $56.800 \mathrm{a}$ & $56.358 \mathrm{a}$ & $1,037 \mathrm{a}$ & $0,924 \mathrm{a}$ \\
\hline MBLE & $54.137 \mathrm{a}$ & $50.388 b$ & $0,925 \mathrm{a}$ & $0,924 \mathrm{a}$ \\
\hline \multicolumn{5}{|l|}{ DMS } \\
\hline $\mathrm{E}$ & 7.681 & 4.029 & 0,131 & 0,066 \\
\hline $\mathrm{MC}$ & 10.862 & 5.698 & 0,186 & 0,094 \\
\hline $\mathrm{CV}(\%)$ & 19,6 & 10,0 & 17,9 & 9,6 \\
\hline
\end{tabular}


forrageira na entrelinha proporcionou o maior número de grãos, e o cultivo consorciado na linha resultou no menor número de grãos.

A massa de 100 grãos foi afetada pela interação dos fatores nos dois anos agrícolas (Tabela 6). No primeiro ano, o desdobramento da interação de modalidades de cultivo, dentro de espaçamentos, verificou-se que houve efeito em ambos os espaçamentos. No espaçamento de $0,90 \mathrm{~m}$, o milho solteiro proporcionou menor massa de grãos e diferiu do cultivo consorciado na linha. No espaçamento de $0,45 \mathrm{~m}$, a maior massa de grãos foi obtida com os cultivos de milho solteiro e consorciado na linha, que foram diferentes do consórcio com braquiária na entrelinha. No desdobramento de

Tabela 4. Desdobramento da interação modalidades de cultivo x espaçamentos entre linhas, para estande final de plantas e índice de espigas de milho consorciado com Brachiaria brizantha, em sistema de plantio direto, no ano agrícola 2003/2004(1).

\begin{tabular}{ccccc}
\hline \multirow{2}{*}{$\begin{array}{c}\text { Espaçamento } \\
(\mathrm{m})\end{array}$} & MCS & \multicolumn{4}{c}{ MBdalidades de cultivo } & MBE & MBLE \\
\cline { 2 - 5 } & \multicolumn{5}{c}{ Estande final (plantas ha $\left.{ }^{-1}\right)$} \\
0,90 & $55.900 \mathrm{ABa}$ & $59.808 \mathrm{Aa}$ & $53.384 \mathrm{ABb}$ & $50.636 \mathrm{Ba}$ \\
0,45 & $59.883 \mathrm{Aa}$ & $48.908 \mathrm{Bb}$ & $61.656 \mathrm{Aa}$ & $50.141 \mathrm{Ba}$ \\
\hline \multicolumn{5}{c}{ Índice de espigas (número de espigas por planta) } \\
0,90 & $0,93 \mathrm{Ab}$ & $0,86 \mathrm{Aa}$ & $0,88 \mathrm{Aa}$ & $0,92 \mathrm{Aa}$ \\
0,45 & $1,08 \mathrm{Aa}$ & $0,99 \mathrm{ABa}$ & $0,95 \mathrm{Ba}$ & $0,92 \mathrm{Ba}$ \\
\hline
\end{tabular}

(1)Médias seguidas por letras iguais, maiúsculas nas linhas e minúsculas nas colunas, não diferem entre si pelo teste DMS, a 5\% de probabilidade; MCS: milho solteiro; MBL: milho + B. brizantha na linha; MBE: milho $+B$. brizantha na entrelinha; MBLE: milho $+B$. brizantha na linha e entrelinha; DMS $=8.058$ plantas ha ${ }^{-1}$ e 0,13 espigas por planta. espaçamentos, dentro de modalidades de cultivo, constatou-se que houve efeito apenas no cultivo de milho solteiro, em que o espaçamento de $0,45 \mathrm{~m}$ proporcionou maior massa de grãos. De maneira geral, na ausência de condições adversas, a competição entre espécies diferentes e o melhor arranjo espacial de plantas, aliado à adubação adequada, promovem a formação de espigas maiores e, conseqüentemente, com maior massa (Borghi et al., 2004), em virtude da maior capacidade fisiológica da planta, decorrente da maior capacidade de absorção de água e nutrientes.

Apesar do efeito da competição, os valores para esta variável foram superiores aos obtidos por Borghi et al. (2004), mesmo quando os autores adotaram o sistema de adubação em função do estande de plantas. Os resultados encontrados no espaçamento de $0,90 \mathrm{~m}$ não eram esperados, uma vez que a competição entre o milho e a forrageira não resultou em menor massa de 100 grãos.

No ano agrícola 2003/2004, com relação ao desdobramento de modalidades de cultivo dentro de espaçamentos, observou-se que houve efeito em ambos os espaçamentos. No espaçamento de $0,90 \mathrm{~m}$, o cultivo de milho solteiro proporcionou maior massa de 100 grãos e diferiu do cultivo com a forrageira semeada na entrelinha. No espaçamento de $0,45 \mathrm{~m}$, a maior produtividade foi proporcionada pelo cultivo consorciado na entrelinha, que diferiu do consórcio na linha e na linha mais entrelinha. No desdobramento de espaçamentos, dentro de modalidades de cultivo, constatou-se efeito significativo no cultivo de milho consorciado na linha e na entrelinha, em que o espaçamento de $0,45 \mathrm{~m}$ proporcionou maior massa de 100 grãos.

Tabela 5. Médias de número de grãos por espiga, massa de 100 grãos e produtividade de grãos do milho consorciado com Brachiaria brizantha, em sistema plantio direto, nos anos agrícolas de 2002/2003 e 2003/2004(1).

\begin{tabular}{|c|c|c|c|c|c|c|c|}
\hline \multirow[t]{2}{*}{ Tratamento } & \multicolumn{2}{|c|}{ Número de grãos por espiga } & \multicolumn{2}{|c|}{ Massa de 100 grãos $(\mathrm{g})$} & \multicolumn{3}{|c|}{ Produtividade de grãos $\left(\mathrm{kg} \mathrm{ha}^{-1}\right)$} \\
\hline & $2002 / 2003$ & $2003 / 2004$ & $2002 / 2003$ & $2003 / 2004$ & $2002 / 2003$ & $2003 / 2004$ & Média \\
\hline \multicolumn{8}{|c|}{ Espaçamento (E) (m) } \\
\hline 0,90 & $521 \mathrm{a}$ & $486 \mathrm{a}$ & $35,9 \mathrm{a}$ & $32,8 b$ & $10.532 \mathrm{a}$ & $7.279 b$ & $8.905 a$ \\
\hline 0,45 & $511 \mathrm{a}$ & $512 a$ & $36,2 \mathrm{a}$ & $34,1 \mathrm{a}$ & $10.529 \mathrm{a}$ & $9.368 \mathrm{a}$ & $9.948 \mathrm{a}$ \\
\hline \multicolumn{8}{|c|}{ Modalidades de cultivo (MC) } \\
\hline MCS & $496 a$ & $513 \mathrm{ab}$ & $35,9 \mathrm{ab}$ & $33,7 \mathrm{a}$ & $10.856 \mathrm{a}$ & $9.747 \mathrm{a}$ & $10.301 \mathrm{a}$ \\
\hline MBL & $511 \mathrm{a}$ & $475 b$ & $37,2 \mathrm{a}$ & $33,7 \mathrm{a}$ & $11.193 \mathrm{a}$ & $8.297 b$ & $9.745 \mathrm{a}$ \\
\hline MBE & $527 \mathrm{a}$ & $523 a$ & $35,8 \mathrm{ab}$ & $33,4 \mathrm{a}$ & $10.913 \mathrm{a}$ & $7.702 b$ & $9.307 \mathrm{ab}$ \\
\hline MBLE & $531 \mathrm{a}$ & $486 \mathrm{ab}$ & $35,4 \mathrm{~b}$ & $33,0 \mathrm{a}$ & $9.161 \mathrm{~b}$ & $7.548 \mathrm{~b}$ & $8.354 b$ \\
\hline \multicolumn{8}{|l|}{ DMS } \\
\hline $\mathrm{E}$ & 36 & 33 & 1,1 & 0,98 & 1.148 & 969 & 1.058 \\
\hline $\mathrm{MC}$ & 50 & 47 & 1,6 & 1,93 & 1.623 & 685 & 1.154 \\
\hline CV (\%) & 9,4 & 9,0 & 4,3 & 4,0 & 14,8 & 11,0 & 13,1 \\
\hline
\end{tabular}

${ }^{(1)}$ Médias seguidas por letras iguais, nas colunas, dentro de espaçamento e modalidade de cultivo, não diferem entre si pelo teste DMS, a 5\% de probabilidade; MCS: milho solteiro; MBL: milho + B. brizantha na linha; MBE: milho + B. brizantha na entrelinha; MBLE: milho + B. brizantha na linha e entrelinha. 
Os resultados de massa de 100 grãos, relacionados aos efeitos das modalidades de cultivo, são complexos e de difícil explicação, pois haveria necessidade de avaliações mais específicas como interceptação da radiação incidente, índice de área foliar, envergadura da folha, desfolhamento etc. Segundo Andrade et al. (2002), a resposta do milho à redução no espaçamento entre linhas está relacionada à radiação incidente na época de florescimento, este é o período crítico na determinação do número de grãos, que determinará a translocação de fotoassimilados para a espiga e os acréscimos na produtividade. Em geral, esta capacidade de interceptação da radiação incidente está relacionada ao índice de área foliar (Amaral Filho et al., 2005), pois fatores como envergadura da folha, desfolhamento, deficiência de nutrientes, e condições de stress das plantas, por causa da seca, comprometem os processos fisiológicos da planta, e ao se adotar a redução no espaçamento entre linhas, alguns destes fatores tendem a ser minimizados, pelo melhor arranjo espacial entre as plantas na área (Argenta et al., 2001; Andrade et al., 2002).

A produtividade de grãos também sofreu influência da interação entre as modalidades de cultivo e espaçamento (Tabela 6). No ano agrícola 2002/2003, com relação ao desdobramento da interação modalidades de cultivo dentro de espaçamento, constatou-se que no espaçamento de $0,45 \mathrm{~m}$ o cultivo da forrageira na linha mais entrelinha do milho reduziu significativamente a produtividade de grãos, em virtude da grande competição entre as espécies, o que acarretou a redução de $2.936 \mathrm{~kg} \mathrm{ha}^{-1}$, em relação ao cultivo do milho solteiro. Embora a consorciação não tenha provocado diferenças em determinadas características da planta de milho, o efeito sinérgico dos menores valores do estande final, do índice de espiga e da massa de 100 grãos pode ser a causa da menor produtividade de grãos no espaçamento de $0,45 \mathrm{~m}$, com o cultivo da forrageira na linha mais entrelinha. Kluthcouski et al. (2000) também verificaram que a produtividade do milho consorciado com a B. brizantha cultivar Marandu, com sementes misturadas ao adubo e distribuídas na linha da cultura, não sofreu redução significativa em relação ao cultivo do milho solteiro.

No segundo ano agrícola (2003/2004), nos dois espaçamentos, houve efeito das modalidades de cultivo. No espaçamento de $0,90 \mathrm{~m}$, o consórcio reduziu significativamente a produtividade de grãos, independentemente da modalidade, enquanto no espaçamento de $0,45 \mathrm{~m}$ houve diferença significativa, em relação ao cultivo solteiro, apenas das modalidades com braquiária na entrelinha e na linha mais entrelinha. Esse efeito foi resultante da imobilização de nutrientes, principalmente de $\mathrm{N}$, provavelmente em virtude da grande quantidade de palhada, presente nas parcelas

Tabela 6. Desdobramento da interação modalidades de cultivo x espaçamentos entre linhas, referente ao número de grãos por espiga (2003/2004) e à massa de 100 grãos (2002/2003 e 2003/2004) do milho consorciado com Brachiaria brizantha, em sistema plantio direto $^{(1)}$.

\begin{tabular}{|c|c|c|c|c|}
\hline \multirow{2}{*}{$\begin{array}{l}\text { Espaçamento } \\
(\mathrm{m})\end{array}$} & \multicolumn{4}{|c|}{ Modalidades de cultivo } \\
\hline & MCS & MBL & MBE & MBLE \\
\hline & \multicolumn{4}{|c|}{ Número de grãos por espiga (2003/2004) } \\
\hline 0,90 & $508 \mathrm{aA}$ & $471 \mathrm{aA}$ & $490 \mathrm{bA}$ & $477 \mathrm{aA}$ \\
\hline \multirow{2}{*}{0,45} & $518 \mathrm{aAB}$ & $480 \mathrm{aB}$ & $557 \mathrm{aA}$ & $495 \mathrm{aAB}$ \\
\hline & \multicolumn{4}{|c|}{ Massa (g) de 100 grãos (2002/2003) } \\
\hline 0,90 & $34,1 \mathrm{bB}$ & $37,6 \mathrm{aA}$ & $35,5 \mathrm{aAB}$ & $36,3 \mathrm{aAB}$ \\
\hline \multirow[t]{2}{*}{0,45} & $37,7 \mathrm{aA}$ & $36,8 \mathrm{aA}$ & $36,0 \mathrm{aB}$ & $34,4 \mathrm{aAB}$ \\
\hline & \multicolumn{4}{|c|}{ Massa (g) de 100 grãos $(2003 / 2004)$} \\
\hline 0,90 & $33,5 \mathrm{aA}$ & $32,8 \mathrm{bAB}$ & $31,4 \mathrm{bB}$ & $33,3 \mathrm{aAB}$ \\
\hline \multirow[t]{2}{*}{0,45} & $33,9 \mathrm{aAB}$ & $34,5 \mathrm{aAB}$ & $35,4 \mathrm{aA}$ & $32,7 \mathrm{aB}$ \\
\hline & \multicolumn{4}{|c|}{ Produtividade $\left(\mathrm{kg} \mathrm{ha}^{-1}\right)$ de grãos $(2002 / 2003)$} \\
\hline 0,90 & $10.181 \mathrm{aA}$ & $11.481 \mathrm{aA}$ & $10.741 \mathrm{aA}$ & $9.727 \mathrm{aA}$ \\
\hline \multirow[t]{2}{*}{0,45} & $11.530 \mathrm{aA}$ & $10.905 \mathrm{aA}$ & $11.086 \mathrm{aA}$ & $8.594 \mathrm{aB}$ \\
\hline & \multicolumn{4}{|c|}{ Produtividade $\left(\mathrm{kg} \mathrm{ha}^{-1}\right)$ de grãos $(2003 / 2004)$} \\
\hline 0,90 & $9.115 \mathrm{aA}$ & $6.993 \mathrm{bB}$ & $6.610 \mathrm{bB}$ & $6.399 \mathrm{bB}$ \\
\hline \multirow[t]{2}{*}{0,45} & $10.379 \mathrm{aA}$ & $9.601 \mathrm{aAB}$ & $8.794 \mathrm{aB}$ & $8.697 \mathrm{aB}$ \\
\hline & \multicolumn{4}{|c|}{ Produtividade $\left(\mathrm{kg} \mathrm{ha}^{-1}\right)$ de grãos (média dos dois anos) } \\
\hline 0,90 & $9.648 \mathrm{aA}$ & $9.222 \mathrm{aA}$ & $8.675 \mathrm{aA}$ & $8.063 \mathrm{aA}$ \\
\hline 0,45 & $10.954 \mathrm{aA}$ & $10.253 \mathrm{aAB}$ & $9.940 \mathrm{aAB}$ & $8.645 \mathrm{aB}$ \\
\hline
\end{tabular}


em que foi cultivada a forrageira no ano anterior, e em virtude da alta relação $\mathrm{C} / \mathrm{N}$ que essa espécie apresenta.

No desdobramento da interação de espaçamentos dentro de modalidades de cultivo, constatou-se que a utilização de $0,45 \mathrm{~m}$ no sistema consorciado, independentemente da modalidade de consorciação, proporcionou produtividade superior à do espaçamento de $0,90 \mathrm{~m}$ (Tabela 6). Esse resultado pode ser explicado pelo melhor arranjo espacial das plantas de milho, que acarretou melhor desenvolvimento das plantas e, conseqüentemente, maior competição com a forrageira. Alguns autores (Argenta et al., 2001; Penariol et al., 2003; Amaral Filho et al., 2005) constataram incremento na produtividade de grãos, no sistema de cultivo solteiro, com a redução do espaçamento, o que não foi constatado neste trabalho.

Portes et al. (2000), ao avaliar a consorciação das mesmas culturas utilizadas neste experimento, relataram que a deposição das sementes de braquiária a $10 \mathrm{~cm}$ de profundidade, com o fertilizante, retardou a emergência das plântulas da forrageira em aproximadamente cinco dias, e as enfraqueceu além disso, em virtude do sombreamento provocado pelo milho durante o período de consorciação, a forrageira apresentou crescimento lento, em especial pelo fato de ambas as espécies possuírem metabolismo $\mathrm{C}_{4}$ de fixação do $\mathrm{CO}_{2}$, característica que as faz exigentes por luz e proporciona ao milho possibilidade de completar o seu ciclo e de produzir satisfatoriamente.

Na média dos dois anos agrícolas, a produtividade foi afetada apenas pelas modalidades de cultivo no espaçamento de $0,45 \mathrm{~m}$, em que o consórcio da braquiária na linha mais entrelinha reduziu significativamente os valores, em relação ao cultivo solteiro, como consequiência dos resultados obtidos no segundo ano.

\section{Conclusões}

1. A modalidade de consórcio e os espaçamentos de 0,45 e 0,90 m entre linhas não comprometem a absorção de nitrogênio pelo milho e pela Brachiaria brizantha.

2. A produtividade de grãos de milho, no espaçamento de $0,45 \mathrm{~m}$, é menor com o consórcio da $B$. brizantha na linha mais entrelinha.

3. Conforme o ano agrícola, a produtividade de grãos é maior no espaçamento reduzido, quando consorciado com $B$. brizantha, independentemente da modalidade de consórcio.

\section{Agradecimentos}

Ao CNPq, pela bolsa concedida a Carlos Alexandre Costa Crusciol.

\section{Referências}

AMARAL FILHO, J.P.R. do; FORNASIERI FILHO, D.; FARINELLI, R.; BARBOSA, J.C. Espaçamento, densidade populacional e adubação nitrogenada na cultura do milho. Revista Brasileira de Ciência do Solo, v.29, p.467-473, 2005.

ANDRADE, F.H.; CALVIÑO, P.; CIRILO, A.; BARBIERI, P. Yield responses to narrow rows depend on increased radiation interception. Agronomy Journal, v.94, p.975-980, 2002.

ARGENTA, G.; SILVA, P.R.F. da; BORTOLINI, C.G.; FORSTHOFER, E.L.; MANJABOSCO, E.A.; BEHEREGARAY NETO, V. Resposta de híbridos simples de milho à redução no espaçamento entre linhas. Pesquisa Agropecuária Brasileira, v.36, p.71-78, 2001.

BORGHI, E.; MELLO, L.M.M. de; CRUSCIOL, C.A.C. Adubação por área e por planta, densidade populacional e desenvolvimento do milho em função do sistema de manejo do solo. Acta Scientiarum: Agronomy, v.26, p.337-345, 2004.

COBUCCI, T.; KLUTHCOUSKI, J.; AIDAR, H. Sistema Santa Fé: produção de forragem na entressafra. In: WORKSHOP INTERNACIONAL PROGRAMA DE INTEGRAÇÃO AGRICULTURA E PECUÁRIA PARA O DESENVOLVIMENTO SUSTENTÁVEL DAS SAVANAS SULAMERICANAS, 2001, Santo Antonio de Goiás. Anais. Santo Antonio de Goiás: Embrapa Arroz e Feijão, 2001. p.125-135. (Embrapa Arroz e Feijão. Documentos, 123).

EMBRAPA. Centro Nacional de Pesquisa de Solos (Rio de Janeiro, RJ). Sistema brasileiro de classificação dos solos. Rio de Janeiro, 1999. 412p.

FERREIRA, D.F. SISVAR: sistema de análise de variância. Versão 4.2. Lavras: Ufla/DEX, 1999. 1 CD-ROM.

FREITAS, F.C.L.; FERREIRA, L.R.; FERREIRA, F.A.; SANTOS, M.V.; AGNES, E.L.; CARDOSO, A.A.; JAKELAITIS, A. Formação de pastagem via consórcio de Brachiaria brizantha com o milho para silagem no sistema de plantio direto. Planta Daninha, v.23, p.49$58,2005$.

JAKELAITIS, A.; SILVA, A.A.; FERREIRA, L.R.; SILVA, A.F.; FREITAS, F.C.L. Manejo de plantas daninhas no consórcio de milho com capim-braquiária (Brachiaria decumbens). Planta Daninha, v.22, p.553-560, 2004.

JAKELAITIS, A.; SILVA, A.F.; SILVA, A.A.; FERREIRA, L.R.; FREITAS, F.C.L.; VIANA, R.G. Influência de herbicidas e de sistemas de semeadura de Brachiaria brizantha consorciada com milho. Planta Daninha, v.23, p.59-67, 2005.

KLUTHCOUSKI, J.; COBUCCI, T.; AIDAR, H.; YOKOYAMA, L.P.; OLIVEIRA, I.P. de; COSTA, J.L. da S.; SILVA, J.G. da; VILELA, L.; BACELlOS, A. de O.; MAGNABOSCO, C. de U. Sistema Santa Fé: tecnologia Embrapa: integração lavoura-pecuária pelo consórcio de culturas anuais com forrageiras, em áreas de lavoura, 
nos sistemas direto e convencional. Santo Antonio de Goiás: Embrapa Arroz e Feijão, 2000. 28p. (Circular técnica, 38).

KLUTHCOUSKI, J.; YOKOYAMA, L.P. Opções de integração lavoura-pecuária. In: KLUTHCOUSKI, J.; STONE, L.F.; AIDAR, H. Integração lavoura-pecuária. 1.ed. Santo Antonio de Goiás: Embrapa Arroz e Feijão, 2003. p.131-141.

LOMBARDI NETO, F.; DRUGOWICH, M.I. Manual técnico de manejo e conservação de solo e água. Campinas: Cati, 1994. v.2. 168 p.

MALAVOLTA, E.; VITTI, G.C.; OLIVEIRA, S.A. Avaliação do estado nutricional de plantas: princípios e aplicações. Piracicaba: Potafos, 1997. 308p.

OLIVEIRA, I.P. de; KLUTHCOUSKI, J.; YOKOYAMA, L.P.; DUTRA, L.G.; PORTES, T. de A.; SILVA, A.E. da; PINHEIRO, B. da S.; FERREIRA, E. da M. de. Sistema Barreirão: recuperação/ renovação de pastagens degradadas em consórcio com culturas anuais. Goiânia: Embrapa-CNPAF, 1996. 87p. (Embrapa-CNPAF. Documentos, 64).

PENARIOL, F.G.; FORNASIERI FILHO, D.; COICEV, L.; BORDIN, L.; FARINELLI, R. Comportamento de cultivares de milho semeadas em diferentes espaçamentos entre linhas e densidades populacionais, na safrinha. Revista Brasileira de Milho e Sorgo, v.2, p.52-60, 2003.

PORTES, T.A.; CARVALHO, S.I.C.; OLIVEIRA, I.P. de; KLUTHCOUSKI, J. Análise do crescimento de uma cultivar de braquiária em cultivo solteiro e consorciado com cereais. Pesquisa Agropecuária Brasileira, v.35, p.1349-1358, 2000.
RAIJ, B. van; CANTARELLA, H.; QUAGGIO, J.A.; FURLANI, A.M.C. Recomendação de adubação e calagem para o Estado de São Paulo. 2.ed. Campinas: Instituto Agronômico, 1996. 285p. (Boletim técnico, 100).

RAIJ, B. van; QUAGGIO, J.A. Métodos de análise de solo para fins de fertilidade. Campinas: Instituto Agronômico, 1983. 31p. (Boletim técnico, 81).

SANGOI, L.; ALMEIDA, M.L.; SILVA, P.R.F.; ARGENTA, G. Bases morfofisiológicas para maior tolerância dos híbridos modernos de milho a altas densidades de plantas. Bragantia, v.61, p.101-110, 2002.

SANGOI, L.; ENDER, M.; GUIDOLIN, A.F.; ALMEIDA, M.L.; HEBERIE, P.C. Influence of row spacing reduction on maize grain yield in regions with a short summer. Pesquisa Agropecuária Brasileira, v.36, p.861-869, 2001.

SILVA, A.C.; FERREIRA, L.R.; SILVA, A.A.; PAIVA, T.W.B.; SEDIYAMA, C.S. Efeito de doses reduzidas de fluazifop-p-butil no consórcio entre soja e Brachiaria brizantha. Planta Daninha, v.22, p.429-435, 2004.

SILVA, A.R.B. da; BENEZ, S.H. Cultivares de milho: produtividade em diferentes sistemas de manejo de solo e espaçamentos. Energia na Agricultura, v.20, p.77-90, 2005.

ZANINE, A. de M.; SANTOS, E.M.; FERREIRA, D. de J.; CARVALHO, G.G.P. de. Potencialidade da integração lavourapecuária: relação planta-animal. Revista Eletrónica de Veterinaria, v.7, 2006. Disponível em: <http://www.veterinaria.org/revistas/redvet/ n010106/010601.pdf>. Acesso em: 27 nov. 2006. 